\title{
Conflitos, localismos e regionalismos na Colônia Militar de Caseros no Norte do Rio Grande Do Sul no século XIX
}

Kalinka de Oliveira Schmitz ${ }^{1}$ Indaia Dias Lopes ${ }^{2}$

TEDESCO, J. C.; VANIN, A. A. Entre a espada, a cruz e a enxada: a Colônia Militar de Caseros no norte do Rio Grande do Sul (1858-1878). Erechim: All Print, 2018. 392 p.

Na obra Entre a espada, a cruz e a enxada: a Colônia Militar de Caseros no norte do Rio Grande do Sul (1858-1878), João Carlos Tedesco e Alex Vanin remontam, a partir de leves vestígios, a curta existência da Colônia Militar de Caseros, situada, em parte, no atual município de Lagoa Vermelha, e no município de Caseros - que leva ainda o nome do núcleo colonial e militar -, no estado do Rio Grande do Sul.

Trata-se de um estudo inédito sobre o tema, minucioso e detalhado, pautado em documentação primária, que busca localizar e situar a Colônia Militar de Caseros na formação histórica da região, articulando a presença indígena à formação de uma colônia. Nota-se que há um silenciamento sobre essa experiência, tanto na historiografia quanto na memória regional, entretanto, nas recentes disputas pela posse da terra envolvendo diferentes sujeitos, há indícios de ocupação remota, que remontam ao período da Colônia Militar, embora descontextualizados e jogando a favor de interesses específicos.

Na primeira parte do livro, os autores discutem alguns elementos que contribuíram para a formação das colônias militares no Brasil, identificando as suas intenções, premências, alterações e os seus significados. Vários elementos contribuíram para a implementação das colônias militares, além das questões geográfico-territoriais. Cabe ressaltar as questões de colonização: havia o intuito de atrair pessoas para o interior do Brasil, por meio de frentes de expansão territorial, ocupacional e produtiva, bem como com o objetivo de coibir os ataques dos povos indígenas.

Mas afinal, o que era uma colônia militar e qual era o seu propósito? As colônias militares do século XIX tinham como objetivo cumprir algumas funções essenciais para que o Império pudesse

1 Universidade de Passo Fundo, Passo Fundo, RS, Brasil. Mestre em História (PPGH/UPF), Passo Fundo, RS, Brasil. ORCID: http:// orcid.org/0000-0001-8457-2951. E-mail: kalinka.oschmitz@gmail.com

2 Universidade de Passo Fundo, Passo Fundo, RS, Brasil. Mestra em Desenvolvimento Regional (PPGDR/Unijuí). Doutoranda em História (PPGH/UPF), Passo Fundo, RS, Brasil. ORCID: https://orcid.org/0000-0003-2966-8461.E-mail: indaia_lopes@yahoo.com.br 
controlar o território, redefinir os espaços e socializar os povos indígenas. As colônias militares eram dotadas de diferentes características e poderiam ser de dois tipos: as fronteiriças e as interioranas. No caso da Colônia Militar de Caseros, era uma colônia militar interiorana, reunindo em uma mesma colônia militares e indígenas da parcialidade Kaingang, e foi o único empreendimento militar no extremo Sul do Brasil com essa tipologia. A segunda colônia militar, situada no Alto Uruguai (1879), era ainda mais isolada e caracterizava-se como uma colônia de fronteira.

Tanto nas regiões de fronteira quanto nas interioranas era necessário suprir os problemas de segurança, povoamento, colonização, aldeamentos de indígenas e terras férteis para a produção agrícola. Assim, as colônias militares eram uma importante alternativa ao Império, pois serviam como suporte para os possíveis conflitos sociais. Devido às particularidades regionais às quais as colônias deveriam se adequar e às normas básicas que deveriam atender, essas apresentavam diferenças e semelhanças entre si. Em termos de semelhanças, as colônias militares eram um conjunto habitacional que possuía características de quartel militar, pois havia habitações para os diretores e para membros de patentes mais elevadas, também para famílias de militares e de membros civis, e no entorno, havia uma extensão de terras que era utilizada para a produção agrícola.

Conforme os autores, o Brasil de meados do século XIX era um país heterogêneo, onde existiam diversas tensões internas, seja na esfera econômica, seja no âmbito social e racial. Desta forma, existiam constantes conflitos, regionalismos, localismos e nativismos, evidenciando a inexistência de uma unidade e de formação de uma consciência nacional, particularmente no período regencial, compreendido entre 1831-1840. Acreditava-se assim, que a existência de instituições militares em várias regiões do País seria capaz de atenuar essas dificuldades. Somava-se a isso, a extensa dimensão territorial do País, a qual dificultava a administração da Coroa Portuguesa e, posteriormente, do Império brasileiro. Em última instância, estavam embutidas nesse projeto, a expansão da propriedade privada e a pacificação dos indígenas.

As colônias militares que foram criadas no norte do território do Rio Grande do Sul localizavam-se em áreas afastadas da capital e das zonas de colonização, e tinham por objetivo controlar o território e redefinir os espaços reservados à propriedade privada da terra e às parcialidades indígenas. Cabe observar que, a colônia militar foi fundada no mesmo contexto da aprovação da Lei de Terras de 1850 , e a formação das primeiras reservas indígenas no Norte riograndense, em 1845. O mosaico populacional da região era visível, formado majoritariamente por indígenas, organizados em parcialidades; caboclos, entendidos aqui por sua identidade sociocultural; e negros, que aproveitavam a grande densidade de matas para se refugiarem do cativeiro. Economicamente, a região respondia pela extração da erva-mate e pela pecuária; a produção agrícola existia em menor escala, principalmente para subsistência, e foi aumentada posteriormente com a instalação de núcleos coloniais, incluso aí a Colônia Militar de Caseros, que tinha como um de seus objetivos a produção de gêneros alimentícios.

No caso em estudo, a Colônia Militar estava ligada à legitimação da posse de terras e à fixação dos indígenas, transformando-os em agricultores. Contudo, após duas décadas, quando foi extinta, ficou evidente a sua ineficácia. Inúmeros lotes de terras ainda não haviam sido demarcados, permanecendo os seus ocupantes como posseiros; já as áreas que não haviam sido 
destinadas a uma família de colonos, ou utilizadas para a produção agrícola da colônia militar, voltaram a integrar as terras tidas como devolutas, ou seja, de propriedade da esfera pública, que poderia dispor das mesmas como bem entendesse. Cabe destacar que, as terras devolutas eram utilizadas para o pagamento de indenizações, criação de núcleos coloniais públicos, e também para venda a particulares, que via de regra, as adquiriam com o compromisso de ocupá-las.

No tocante ao aspecto militar, os autores pontuam que as tropas localizadas no posto militar não eram formadas por militares de carreira, mas sim, por membros da população caboclos e colonos - que circundam a Colônia Militar. Por não serem militares de carreira, os componentes das tropas exerciam outras atividades paralelas ao posto militar, notadamente a agricultura. Como resultado da falta de preparo específico ao cumprimento de atividades militares, e do pequeno destacamento reunido, o serviço de proteção às localidades próximas, que vez ou outra eram requeridos, acabava sendo abaixo do mínimo necessário.

Na segunda parte da obra, os autores partem da discussão de que a proteção e a contenção dos indígenas na região não era o foco central do projeto da colônia militar. Segundo o estudo, a Colônia Militar contribuiu para a diminuição de conflitos e restrição do espaço indígena, o qual passou a ser utilizado para instalação do grande latifúndio e, posteriormente, de empreendimentos coloniais. Nesse sentido, os autores afirmam que a criação da colônia militar restringiu a autonomia de circulação dos indígenas, ao passo que auxiliou a privatização da terra, em consonância com as políticas públicas do período.

O encerramento das atividades da Colônia Militar de Caseros em 1878, deu-se em função de múltiplos motivos. Pela grande variedade de indivíduos e interesses ali envolvidos, o cenário de desenvolvimento da Colônia Militar se fazia complexo. Não poderia ser diferente, uma vez que a existência de interesses distintos contribuiu sobremaneira para o surgimento de conflitos e tensões que acabavam por prejudicar o pleno desenvolvimento da Colônia Militar. Para decretar o encerramento das atividades, foi levado em consideração a produção agrícola, tanto a venda do excedente quanto o suprimento de toda a população colonial ali presente. A colônia padecia de diferentes problemas para a produção agrícola, decorrentes de questões climáticas, somada a má qualidade da terra, cuja produção era inferior ao esperado, além da falta de investimento público. A população da colônia chegou a somar mais de 260 pessoas em 1875, entre militares, indígenas, colonos e agregados.

A convivência em um determinado local não garantiria o fim de pré-conceitos entre si; um exemplo é o incentivo ao consumo de álcool pelos indígenas (era vedado o consumo aos índios), para desestabilizá-los e causar punições aos mesmos; e problemas de insubordinação ante à hierarquia militar presente. A colônia militar também recebeu o padre Antonio de Moraes Branco, que dentre vários aspectos peculiares apontados pelos autores, havia contraído matrimônio e tido filhos, e cuidava além dos serviços religiosos, da saúde dos habitantes dali, através da botica que mantinha. A colônia era então, palco de diversas peculiaridades em seu cotidiano.

Ao fim das atividades oficiais do núcleo colonial militarizado, houve a dispersão populacional, e a localidade de Caseros passou a incorporar a Freguesia de Lagoa Vermelha. Como anteriormente destacado, a questão de terras, mesmo que em segundo plano, tinha grande importância no 
cenário de atuação da Colônia Militar de Caseros. Ao ser desmantelada a organização da Colônia Militar, as terras que a formavam tiveram diferentes destinos: as que já haviam sido demarcadas e entregues aos colonos foram mantidas assim, enquanto o restante retornou ao status de devolutas.

Na condição de terras devolutas, a área foi apossada pelos posseiros já instalados, por proprietários e posseiros das imediações passaram a incorporar áreas da antiga colônia, bem como os colonos da ex-colônia, buscavam expandir as suas propriedades para áreas agora devolutas. Ademais, fazendas foram formadas e expandidas via apropriação de partes das terras que haviam composto a antiga Colônia Militar, sendo citadas pelos autores, principalmente as Fazendas do Ligeiro e da Limeira.

Houve casos em que as terras apossadas se tornaram novamente núcleos coloniais, que passaram então a receber principalmente colonos de origem italiana. Ou seja, mais do que a experiência circunscrita da Colônia Militar de Caseros, o seu desdobramento pós-extinção está na gênese da propriedade da terra da região, envolvendo indígenas, colonos e o poder público desde então.

Os indígenas, antes aldeados no Aldeamento de Santa Izabel, dentro da colônia militar, passam a circular nas proximidades da antiga colônia, sob a liderança de Cacique Doble. De grande importância para a sua parcialidade e representação dos índios, ele participou de comitiva que se deslocou para Porto Alegre em fevereiro de 1864, a fim de ter uma audiência com o presidente do Estado, para reafirmar um acordo entre o Governo e os indígenas rio-grandenses.

Enfim, o livro está organizado em oito capítulos, nos quais os autores discutem a origem das colônias militares, para em seguida, analisar a Colônia Militar de Caseros, a sua rotina e os sujeitos que ali se encontravam, os objetivos e as dificuldades do empreendimento, o cotidiano repleto de problemas que contribuem para a não harmonização da sociabilidade daquele espaço. A documentação utilizada pelos autores como fonte para o estudo foi obtida junto ao Arquivo Histórico do Rio Grande do Sul (AHRS), compostas basicamente por correspondências trocadas entre diretores e capelães da colônia e também pelos diretores do aldeamento indígena com os presidentes da Província.

Além desta documentação do AHRS, os autores também fizeram uso de outros arquivos, como acervos ligados à apropriação da terra na região Norte/Nordeste da província no período de 1854 a 1890. Também visitaram a região onde se localizava a Colônia Militar de Caseros, realizando o levantamento de fontes orais, através de entrevistas com descendentes dos habitantes remanescentes, tanto colonos quanto os indígenas do atual acampamento que existe no local onde ficava situada a colônia. A atual demanda dos indígenas do acampamento de Caseros remonta à ocupação remota da Colônia Militar, embora a memória dessas populações não faça referência à essa experiência.

A obra é, deste modo, resultado de amplo cruzamento de fontes primárias, bem como da grande utilização de mapas para a compreensão do espaço em análise.

Portanto, o livro evidencia a complexidade das colônias militares do século XIX, através da análise da Colônia Militar de Caseros, demonstrando que, se por um lado, foi um fracasso enquanto projeto de colônia por parte do Império, logo, silenciada pela historiografia e pela memória regional; por outro, marcou profundamente a ocupação da região, ampliando a pro- 
priedade privada da terra e as posses irregulares e, principalmente, a exclusão do indígena da área em questão. Assim, a obra fornece elementos para situar e compreender os conflitos históricos pela propriedade da terra, onde as vítimas assumem feições variadas, conforme as políticas de governo. Aponta, ainda, para uma primeira experiência de colonização na região, ampliada e implementada efetivamente na Primeira República, dirigida pelo Governo do Estado.

Por fim, destaca-se a importância da obra resenhada para a historiografia regional, evidenciando que ela é rica em fontes e aborda uma experiência que ainda não havia sido estudada. Mesmo assim, não esgota essa temática, abrindo precedentes para o desenvolvimento de outros estudos sobre as colônias militares.

Recebido em: 25/3/2019.

Aprovado em: 12/4/2019.

\section{Kalinka de Oliveira Schmitz}

Mestre em História na Universidade de Passo Fundo

kalinka.oschmitz@gmail.com

ORCID: http://orcid.org/0000-0001-8457-2951

\section{Indaia Dias Lopes}

Doutoranda em História na Universidade de Passo Fundo

indaia lopes@yahoo.com.br

ORCID: https://orcid.org/0000-0003-2966-8461

Instituição: Universidade de Passo Fundo (UPF). Endereço Postal: Av. Brasil Leste, 285 - São José, Passo Fundo - RS. CEP: 99052-900. 